\begin{tabular}{|c|c|c|}
\hline & 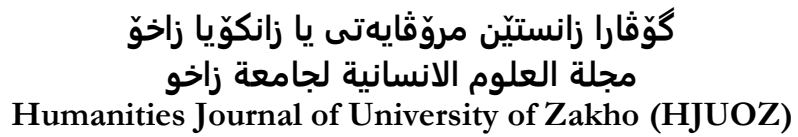 & \\
\hline$\circlearrowright \bigcup \bigcirc z$ & Vol. 8, No. 1, pp. 160-171, March-2020 & $\begin{array}{l}\text { hjuoz.uoz.edu.krd } \\
\text { p-ISSN: 2664-4673 } \\
\text { e-ISSN: 2664-4681 }\end{array}$ \\
\hline
\end{tabular}

\title{
From Wh-Movement to Wh-In-Situ Acquisition of I-To-C Movement in English Interrogative Constructions by Kurdish Learners
}

\author{
Shivan Toma \\ University of Duhok, Kurdistan Region - Iraq.
}

Received: 10.2019/ Accepted: 02. 2020 / Published: 03. 2020 https://doi.org/10.26436/hjuoz.2020.8.1.585

\begin{abstract}
:
In this study, the effect of Kurdish (Behdini variety) as an L1 on L2 learners' acquisition of English Wh-movement in interrogation will be investigated through comparatively taking into account the most current syntactically-based generative models of Second Language Acquisition, including Full Access/Full Transfer (FA/FT) (Schwartz \& Sprouse, 1996), the Interpretability Hypothesis (Tsimpli \& Dimitrakopoulou, 2007), and the Variational Model of Language Acquisition (Yang, 2002). A Grammaticality Judgement Elicitation Task is conducted in the form of a surveying questionnaire to gather data among L2 learners to establish their acquisition process of interrogation in English. The informants are students of the English and Translation Departments at the College of Languages - University of Duhok, English being their second language. The data are analysed using mixed-effects modeling by employing the lmer package (version 3.3.1) with logit link function and binomial variance for the judgement data in R, an open-source language and environment for statistical computing. The results of the study show that there is a transfer from first language into the second language due to the finding that most participants, disregarding their proficiency level, failed to reject the ungrammatical sentences in almost all the categories. The study finds support for the FT/FA proposal, where L1 transfer occurs, in addition to L2 input and access to universal grammar
\end{abstract}

Keywords: Second Language Acquisition (SLA), Wh-fronting, Wh-movement, Wh-in-situ, Behdini Kurdish, Universal Grammar (UG).

\section{Introduction}

This study, in a broad sense, tackles the process of learning a syntactic aspect of a language other than L1. More specifically, it is a developmental study that investigates the development of English interrogation in Behdini Kurdish-speaking learners of EFL. Behdini is a Kurdish language variety mainly spoken in Northern Iraq. This study is an attempt to find out how Kurdish learners of English learn English interrogation and cope with the problem of the movement and the obligatory use of auxiliary in non-subject interrogative constructions in English, which is not the case in Kurdish.

This research is an attempt to explain the transfer issue in terms of its nature and extent from L1 to the syntax of L2 learners. Insights are taken from the Generative Approaches to second language acquisition. As it is known, not only transfer is taken into account in Generative SLA, but the focus is also on the influence of Universal Grammar (UG) on second language learning.

In this study, the effect of Kurdish as an L1 on L2 learners' acquisition of English movement in interrogation will be investigated through comparatively taking into account the most current syntactically-based generative models of SLA, including Full Access/Full Transfer (FA/FT) (Schwartz \& Sprouse, 1996), the Interpretability Hypothesis (Tsimpli \& Dimitrakopoulou, 2007), and the Variational Model of Language Acquisition (Slabakova, 2008).

\section{UG Principles and Parameters}

Principles of UG "define the structural architecture of human language," whereas the "variation between particular languages is accounted for by a small number of parameters of variation allowed within the overall design defined by the principles"
(Hawkins, 2011: 13). All the aspects of the grammar of languages are not possible to be universal; alternatively, the whole natural languages would have been alike and thus there would have been no need to learn grammatical aspects involved in language acquisition.

However, with having the situation as it is (i.e. having both principles and parameters), grammatical learning does not have to involve learning those aspects of grammar which are universal (that is, which are decided by universal grammatical operations and principles). And this would involve only setting the language-specific parameters and the range of parametric variation that could exist in all the natural languages.

The sentences in (1) from English and Kurdish are an example on a type of parametric variation across languages:

(1) a. Azad şitranc-ê di-ket.

Azad chess-OBL PRST-play.3SG

"Azad plays chess."

b. Şitranc-ê di-ket. chess-OBL PRST-play.3SG

"Plays chess."

c. Azad plays chess.

d. *Plays chess.

It is clear from the data expressed in the above sentences that verb can take an overt subject and object both in English and Kurdish. However, in Kurdish the verb can be used without an overt subject (or it has a null subject), but in English the verb plays cannot stand without an overt subject. That is why sentence (d) cannot be grammatical. Kurdish is a null-subject language, but English is not. Thus, one principle may have many parameters depending on diverse languages as illustrated in Diagram 1 below, which is produced by the researcher. 


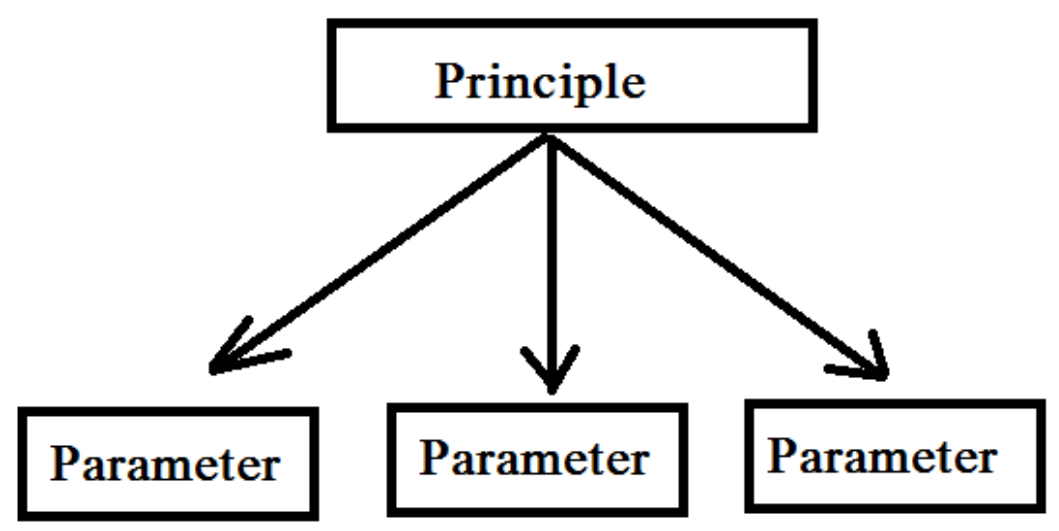

Diagram 1. Principles and parameters

Another variation among languages is the Wh-Parameter, which determines whether Wh-expressions are fronted or not. This parameter is a binary parameter because it allows for two probabilities only. The study is mainly based on this variation.

\subsection{Wh-Movement in English and Kurdish:}

Wh-movement is acceptable and it is compulsory for nonsubject Wh-expressions in English. For instance, in the interrogative structures (2) and (3) the Wh-expressions are moved to the front of the structures:

(2) a. She went to school.

b. Where did she go $t$ ?

(3) a. They ordered coffee.

b. What did they order $t$ ?

However, it seems that in (4b) I-to-C raising in the form of dosupport cannot take place (the construction is acceptable only when do bears emphatic stress). In (3b), on the other hand, where object-movement is involved, subject-aux inversion takes place whereby did moves to $\mathrm{C}$.

(4) a. John left.

b. Who left?

In Kurdish, on the other hand, it is observed that Wh-questions, whether the Wh-expression questions subjects (as in 5) or objects/complements (as in 6), contain in-situ Wh-expressions. This means that the Wh-expressions do not undergo overt Whmovement, as in (5) and (6). These examples are based on the researcher's own intuituions.

(5) a. Heval-î gol tomar kir.

Haval-OBL goal scoring do.PAST- $\varnothing$-3SG

"Haval scored the goal."

b. Kê gol tomar kir?

Who goal scoring do.PAST- $\varnothing$.-3SG

"Who scored the goal?"

(6) a. Tu dê subahî hê-y.

You will tomorrow come-2SG

"You will come tomorrow."

b. Tu dê kengî hê-y?

You will when come-2SG

"When will you come?"

As clear in (5) and (6) the Wh-expressions who and when stay in-situ in Kurdish. As for English, on the other hand, the Whword who (in 2 and 3) stays in-situ but the Wh-word when (as in 4) is moved. This means that I-to-C takes place in English Wh-questions when the sentence questions a non-subject structure (an object or a complement), but it does not take place when the sentence questions a subject. As for Kurdish, I-to-C does not take place in either case.
2.1.1 Auxiliary Use in English and Kurdish Interrogation In default, Wh-questions in English need the use of the auxiliary as in (7). There are cases, however, in which questions in English do not require an auxiliary verb as in (8).

(7) How many workers do you know in that factory?

(8) How many workers work in that factory?

In (7), there is an obligatory need for the auxiliary verb $d o$, whereas in (8) no auxiliary verb is required. Whether to use an auxiliary verb or not, it depends upon the function of the question word in the sentence. If for example "who/what/how" question the subject (agent) not the object (or complement), there is no need for an auxiliary verb. Sentence (9) questions the subject, and therefore there is no need for an auxiliary verb. On the other hand, sentence (10) questions the object and that is why the auxiliary did is used.

(9) Who came here?

(10) Who did you speak with?

As for Yes/No questions, they need the use of the auxiliary as in (11). In the case of the absence of auxiliary, a dummy do is placed before the main verb to act as an auxiliary as in (12). The form and the tense of the inserted do depend on the tense of the main verb and the subject if the verb is in the simple present tense. So do takes either of the three forms do, does, and did.

(11) Is he a student?

(12) Do you work?

As far as interrogation in Kurdish is concerned, it is accomplished without making use of an auxiliary element. For instance:
(13) a. Erê ew kar di-ke-t?
Q.P he working PRST-do-3SG
"Is he working?"
b. Ma wan kar kiriye?
Q.P they working do.PAST
"Have they worked?"

(14) Tu li kîrê kar di-ke-y?

You in where working PRST-do-2SG

"Where do you work?"

It is obvious that for interrogation in Kurdish, whether Yes/No questions (as in 13) or Wh-questions (as in 14), there is no need for any auxiliary elements.

It is to be noted that question markers like Erê and $M a$ are usuually used by native speakers of Behdini Kurdish at the beginning of questions but they are pragmatically, not syntactically, oriented.

2.1.2 A Summary of the Interrogation Comparision between English and Kurdish: 
Comparing the English interrogation with the Kurdish one, it is evident that they differ in some respects but they are similar in some other respects. In English Wh-questions, Wh-movement is acceptable in the form of I-to-C raising in the form of dosupport when the Wh-expression questions a non-subject element (either an object or a complement). However, in subject Wh-questions, the Wh-expression stays in-situ. As for Kurdish, on the other hand, Wh-expressions always stay in-situ and no Wh-movement is involved.

English and Kurdish also differ in Yes/No questions because in English auxiliary verbs should be used which is not the case in Kurdish. They also differ in the necessity of the presence of auxiliaries for interrogating the sentence in English when the Wh-question is about an object or complement which is not the case in Kurdish. On the other hand, English Wh-questions behave similarly to Kurdish questions when the question is about a subject as no auxiliary verb is required.

\section{Research Questions and Hypotheses}

Based on SLA theories of Full Access/Full Transfer (Schwartz \& Sprouse, 1996), the Interpretability Hypothesis (Tsimpli \& Dimitrakopoulou, 2007), the Variational Model of Language Acquisition (Slabakova, 2008), and Direct Access theory (Epstein, Flynn, \& Martohardjono, 1996), the study considers the following main research questions:

(1) How do Kurdish learners of English reanalyse the "support" verb in their complex predicate, especially in relation with English do-support?

(2) How do Kurdish learners of English acquire verb/auxiliary movement to $\mathrm{C}$ ?

(3) Will there be a systematic development by Kurdish learners of English in the process of acquiring Wh-questions and Yes/No questions?

Based on the research questions mentioned above, hypotheses and predictions are summarised below:

1. Kurdish learners of English are predicted to over-accept questions without auxiliary verbs, and that absence of auxiliary verbs in questions is going to take longer to disappear from structures in which they are sometimes licensed in English.

2. Kurdish learners of English are predicted to easily acquire sentences that question the subject where the auxiliary verb is absent due to being compatible with their L1 structures. Positive transfer is, thus, expected to take place.

3. Kurdish learners are predicted to face difficulties in acquiring the sentences that question objects/complements in which auxiliary verbs, unlike their L1 structures, are triggered. So negative transfer is expected to take place.

4. Since Kurdish Wh-questions always contain in-situ words, there will be difficulties for Kurdish learners, especially for less proficient participants, to acquire the verb/auxiliary movement to $\mathrm{C}$ in English.

5. Kurdish learners' English proficiency level is predicted to have a role in the process of their acquisition of questions. This means that beginners are expected to transfer the absence of auxiliary verbs from their L1 into their English interlanguage specifically in object and complement Wh-questions, whereas more advanced participants are expected to be more sensitive to the presence of auxiliary verbs in object Wh-questions.

\section{SLA Theories}

Various predictions are made by different SLA theories regarding the role of transfer and the ultimate attainment to explore whether it is possible for L2 learners to acquire L2 syntactic properties. Transfer is related to the extent to which L1 properties affect second language acquisition (White, 2003). In this section, the theories that contribute to the analysis of the data and that outline the predictions made will be elaborated and explained. These theories are: Full Access/Full Transfer (Schwartz \& Sprouse, 1996), the Interpretability
Hypothesis (Tsimpli \& Dimitrakopoulou, 2007), the Variational Model of Language Acquisition (Yang, 2002), and Direct Access theory (Epstein et al., 1996).

\subsection{Full Access/Full Transfer (Schwartz \& Sprouse, 1996):}

This theory hypothesizes that the initial state of L2 acquisition is the final state of LI acquisition (Full Transfer) and that failure to assign a representation to input data will force subsequent restructurings, drawing from options of UG (Full Access).

This means that Kurdish L2 learners at lower proficiency levels are expected to follow their L1 structures. That is, they will not be able to acquire the Wh-movement in the form of I-to-C raising in the form of do-support in objective constructions. Due to positive transfer, however, Kurdish learners are expected to make positive judgements regarding subjective constructions which are compatible to their L1 structures as in both languages they stay in-situ. However, as participants' English language proficincy level increases, there will be full access to UG and the judgements will be enhanced.

Moreover, Kurdish learners at lower proficiency levels are also expected to fail in the acquisition of auxiliaries used in object Wh-constructions. On the other hand, more proficient L2 learners are expected to perform better.

\subsection{The Interpretability Hypothesis (Tsimpli \& Dimitrakopoulou, 2007):}

This hypothesis proposes that the uninterpretable features that are not instantiated in the L1 are inaccessible in adult L2 acquisition. These features would effectively posit a selective locus for fossilization or the loss of the capacity for acquisition beyond the critical period.

Based on the assumptions of this hypothesis, Kurdish L2 learners, especially at lower proficiency levels, are expected to face notable difficulties in acquiring the Wh-movement in English objective constructions due to their inability to set the parameter into Wh-fronting.

\subsection{The Variational Model of Language Acquisition (Yang,} 2002):

This model suggests that all UG-defined grammars are accessible to L2 learners at the beginning, and that language acquisition is a process of competition among these grammars. Based on this assumption, the acquisition of I-to-C movement in English interrogative constructions might be a case of competition for Kurdish learners between the Wh-Parameter two possibilities: whether Wh-expressions are fronted or not, rather than being explained based on the traditional model of parameter-setting.

\subsection{The Direct Access theory (Epstein, Flynn, \& Martohardjono, 1996):}

If the FA/FT (Schwartz \& Sprouse, 1996) posits L1 transfer and considers the L1 grammar to be the starting point for the acquisition of L2, the Direct Access theory, on the other hand, takes UG as the starting point for the acquisition of $\mathrm{L} 2$.

\section{Data Analysis: A Judgement Elicitation Task}

\subsection{Design and Methodology:}

This study is experimantal, and it is based on quantitative data. The study instruments are prepared by the researcher. A jury consisting of three members have decided its validity and suitability for conducting this study (see Appendix 1).

This experiment involves a Judgement Elicitation Task (JET), which seeks to investigate the L2 learners' grammatical representations.

\subsection{Participants, Instruments, and Procedure:}

Overall, 40 participants took part in this study. All of them were Kurdish speakers with English as their second language and they were all students at the University of Duhok, College of 
Languages, Departments of English and Translation. 28 of the participants were females and 12 were males. Their ages ranged from 20 to 30 years old.

A Grammaticality Judgement Task (GJT) was utilised to examine the participants' knowledge (see Appendix 2). A questionnaire was involved in the GJT to elicit some personal information about the participants' background.
Data were collected in a one-hour session with two different tasks: one to conduct the GJT and one to examine the students' English language proficiency level (see Appendix 3).

In this session, students did not get any feedback on whmovement to avoid making them aware of the task since this is an acquisition study that depends on participants' inherent and intuitive knowledge.

Table 1 previews the participants' characteristics.

Table 1: Kurdish Participants' Characteristics

\begin{tabular}{l|l}
\hline Number & $40(12$ males and 28 females $)$ \\
\hline Age range & $20-30$ (mean $=25$ years old $)$ \\
\hline Proficiency & Low level $=19$ (Scores: $20,25,27.5,27.5,30,30,35,35,35,37.5,37.5,40$, \\
& $40,40,42.5,47.5,47.5,47.5,47.5)$ \\
& Intermediate level $=14$ (Scores: $52.5,52.5,52.5,55,55,57.5,57.5,57.5,60$, \\
& $62.5,65,65,65,67.5)$ \\
& Advanced level $=7(70,72.5,75,77.5,80,82.5,87.5)$ \\
\hline
\end{tabular}

The proficiency variable measures each participant's English language proficiency level out of $100 \%$. The test is based on a proficiency test that is accredited from Oxford University.
Participants' scores, as shown in Table 1, ranged between $20 \%$ and $87.5 \%$. The L2 learners' proficiency levels are previewed in Figure 1.

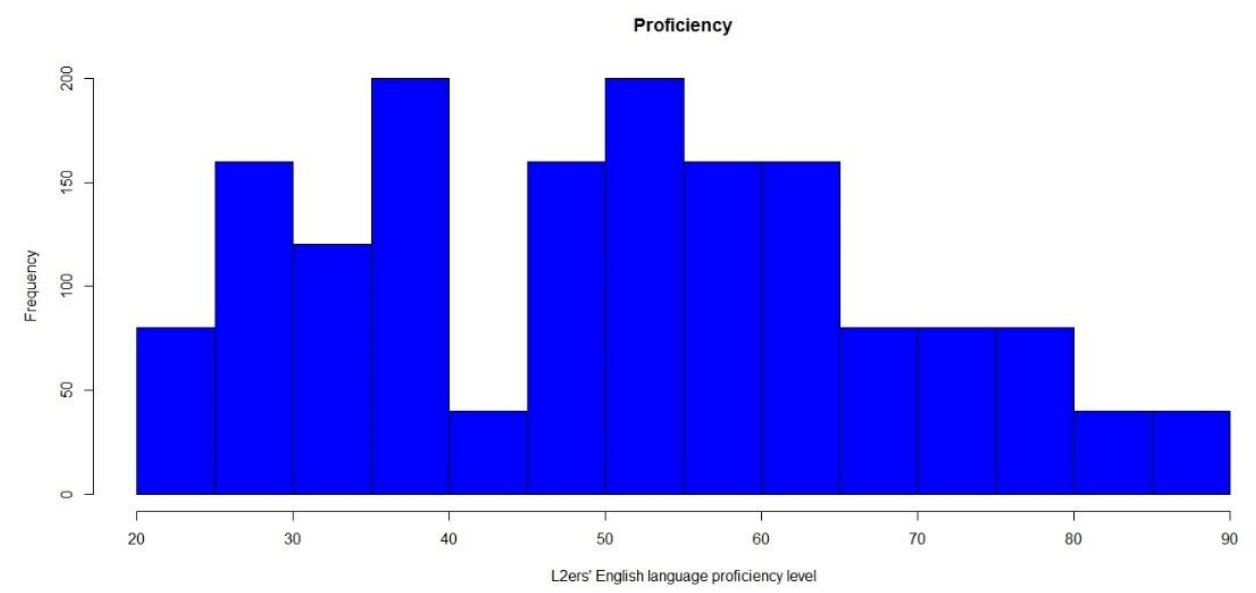

Fifure 1: Kurdish learners' English language proficiency level

The test comprised 40 four-choice items which were Whquestions and yes/no questions on the basis of Wh-movement and the use of do-support and auxiliary verbs in addition to five filler-gap items. The participants were asked to read the sentences carefully and then judge whether the given questionsentences (as in Table 2) were grammatical or ungrammatical in English. The informants were asked to check the correct choice based on their intuitions. No time limits were imposed on them while taking the test.

Table 2. Samples of the test items

\begin{tabular}{c|l|c|c}
\hline$\#$ & \multicolumn{1}{|c|}{ Sentences } & Grammatical & Ungrammatical \\
\hline 1 & Do they live in Australia? & & \\
\hline 2 & How many workers you know in that factory? & & \\
\hline
\end{tabular}

\subsection{Description and Distribution of Data:}

Apart from the filler-gap items, test items were 40 sentences: 16 sentences were Yes/No questions and 24 sentences were Wh-questions. The main variables are participants, L2ers' proficiency level, item texts, item number, question type, I-toC movement, auxiliary, argument, grammaticalness, gender, age, and rating. A full description of the dataset used is provided in Table 3 below showing all the variables with their factors.

Table 3. Description of the data

\begin{tabular}{|c|c|c|}
\hline \multicolumn{2}{|l|}{ Dataset and R script } & Dat.csv; My script.R \\
\hline \multicolumn{2}{|l|}{ Size of dataset: } & 1600 obs. of 12 variables \\
\hline Predictors & Factors & Conditions \\
\hline \multirow[t]{2}{*}{ Random effects } & Participant & Anonymised Kurdish learners: P1 to P40. \\
\hline & Item.number & $\begin{array}{l}\text { This shows the randomised numbers for the order in } \\
\text { which the sentences are presented in the test from } 1 \text { to } \\
40 \text {. }\end{array}$ \\
\hline
\end{tabular}




\begin{tabular}{|c|c|c|}
\hline \multirow[t]{8}{*}{ Fixed effects } & Question.type & Wh-question vs. Yes/No.question \\
\hline & I.to.C.movement & Wh-movement vs. Wh-in-situ \\
\hline & Auxiliary & $\begin{array}{l}\text { Yes vs. No (Yes denotes that the sentence contains an } \\
\text { auxiliary and No denotes that the sentence does not } \\
\text { contain an auxiliary) }\end{array}$ \\
\hline & Argument & $\begin{array}{l}\text { Non-subject vs. subject (Non-subject indicates that the } \\
\text { sentence questions an object or a complement, while } \\
\text { Subject indicates that the sentence questions a subject) }\end{array}$ \\
\hline & Proficiency & $\begin{array}{l}\text { Learners' English language level based on the scores } \\
\text { they got (it is ranged from } 20 \% \text { to } 87.5 \% \text { ) }\end{array}$ \\
\hline & Grammaticalness & Grammatical vs. Ungrammatical \\
\hline & Gender & Male vs. Female \\
\hline & Age & $20-30$ \\
\hline Dependent variable & Rating & Grammatical vs. Ungrammatical \\
\hline
\end{tabular}

\section{Data Analysis and Discussion of the Results}

In this section, a general overview of the results in the acceptance rates is presented to make it easier to follow the discussion of the results.

Table 4 and Figure 2 show the general results of the question type, i.e. whether the test items are Wh-questions or Yes/No questions. The participants highly rated the grammatical sentences both for Wh-questions (80\%) and Yes/No questions (79\%). However, the judgements are not categorical because the informants failed to reject the ungrammatical sentences, especially concerning Wh-questions as $46 \%$ of them accepted the ungrammatical sentences.

Table 4: Acceptance Rates of the Question Type

\begin{tabular}{l|l|l|l|l|l|l|l|l}
\hline \multirow{2}{*}{ Rating } & \multicolumn{2}{l|}{ Wh-questions } & \multicolumn{2}{l}{ Yes/No questions } \\
\cline { 2 - 9 } & \multicolumn{2}{l|}{ Grammatical } & \multicolumn{2}{l}{ Ungrammatical } & \multicolumn{2}{l}{ Grammatical } & \multicolumn{2}{l}{ Ungrammatical } \\
\hline 1 (Good) & $80 \%$ & 515 & $46 \%$ & 148 & $79 \%$ & 252 & $27 \%$ & 86 \\
\hline $2(\mathrm{Bad})$ & $20 \%$ & 125 & $54 \%$ & 172 & $21 \%$ & 68 & $73 \%$ & 234 \\
& & & & & & & & \\
\hline
\end{tabular}

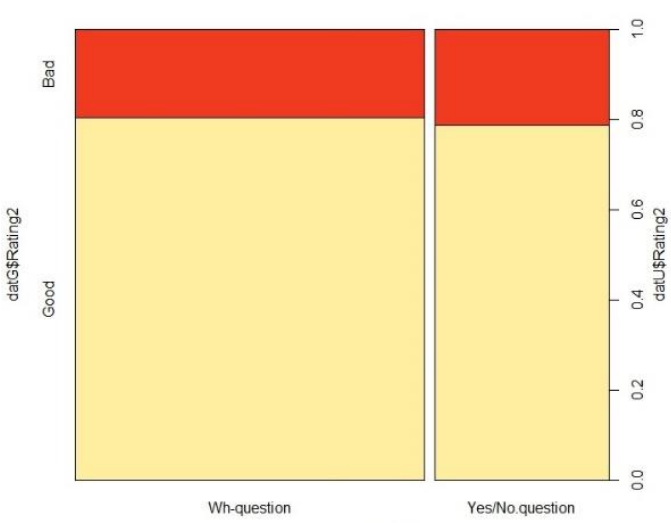

Grammatical Sentences

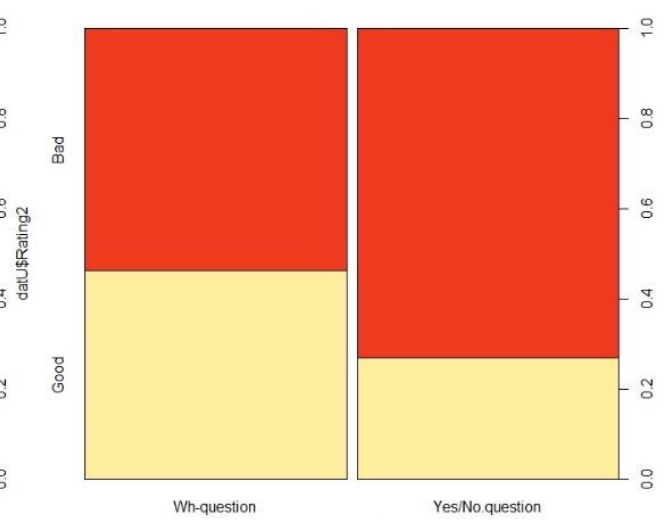

Ungrammatical Sentences

Figure 2: Acceptance Rates of the Question Type

As shown in Table 5 and Figure 3, Kurdish learners have successfully acquired the Wh-movement and Wh-in-situ parameters, as $81 \%$ of participants accepted the Wh-movement grammatical sentences and $80 \%$ accepted the Wh-in-situ sentences. However, they have interestingly failed to reject the ungrammatical Wh-movement sentences with a 64\% acceptance rate, whereas only $36 \%$ of participants rejected the ungrammatical sentences. This is not the case in the Wh-in-situ sentences as the majority of participants with $72 \%$ rejected the ungrammatical sentences. This could be traced back to the fact that the ungrammatical Wh-movement sentences are compatible with the L2ers' L1 structures and thus a negative transfer is obviously assumed to be triggered. 
Table 5: Acceptance Rates of the I-to-C Movement

\begin{tabular}{|c|c|c|c|c|c|c|c|c|}
\hline \multirow{3}{*}{$\begin{array}{l}\text { Rating } \\
1 \text { (Good) }\end{array}$} & \multicolumn{4}{|c|}{ Wh-movement } & \multicolumn{4}{|c|}{ Wh-in-situ } \\
\hline & \multicolumn{2}{|c|}{ Grammatical } & \multicolumn{2}{|c|}{ Ungrammatical } & \multicolumn{2}{|c|}{ Grammatical } & \multicolumn{2}{|c|}{ Ungrammatical } \\
\hline & $81 \%$ & 259 & $64 \%$ & 102 & $79 \%$ & 508 & $28 \%$ & 132 \\
\hline $2(\mathrm{Bad})$ & $19 \%$ & 61 & $36 \%$ & 58 & $21 \%$ & 132 & $72 \%$ & 348 \\
\hline
\end{tabular}

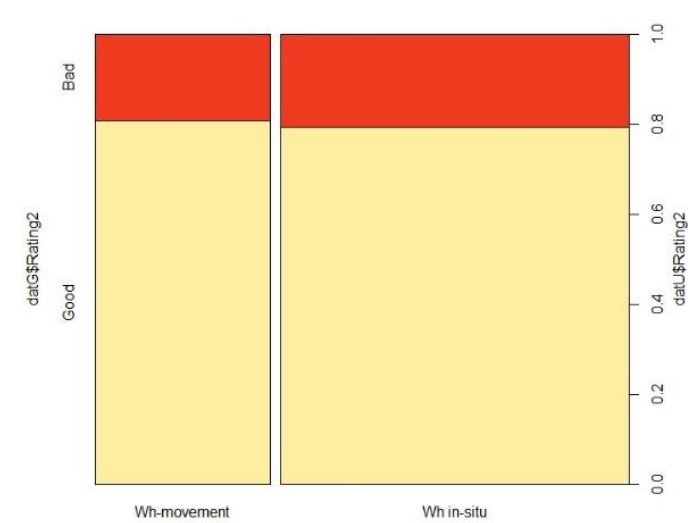

Grammatical Sentences

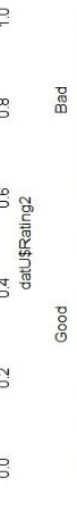
The judgement rates for the argument structure, which shows
whether a sentence questions a subject or a non-subject element, are previewed in Table 6 and Figure 4. The same dynamic of acceptance rates is repeated with the argument variable as Kurdish learners categorically accepted the grammatical sentences of non-subject and subject arguments

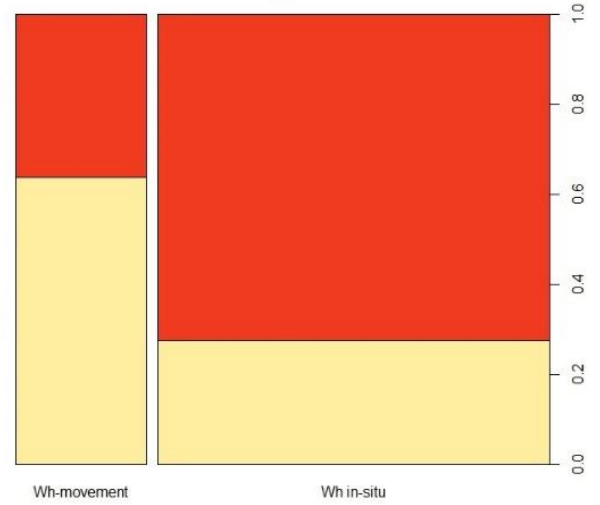

Ungrammatical Sentences

Table 6: Acceptance Rates of the Argument Structure

\begin{tabular}{|c|c|c|c|c|c|c|c|c|}
\hline \multirow{3}{*}{$\begin{array}{l}\text { Rating } \\
1 \text { (Good) }\end{array}$} & \multicolumn{4}{|c|}{ Non-subject } & \multicolumn{4}{|c|}{ Subject } \\
\hline & \multicolumn{2}{|c|}{ Grammatical } & \multicolumn{2}{|c|}{ Ungrammatical } & \multicolumn{2}{|c|}{ Grammatical } & \multicolumn{2}{|c|}{ Ungrammatical } \\
\hline & $81 \%$ & 259 & $46 \%$ & 148 & $79 \%$ & 508 & $27 \%$ & 86 \\
\hline 2 (Bad) & $19 \%$ & 61 & $54 \%$ & 172 & $21 \%$ & 132 & $73 \%$ & 234 \\
\hline
\end{tabular}

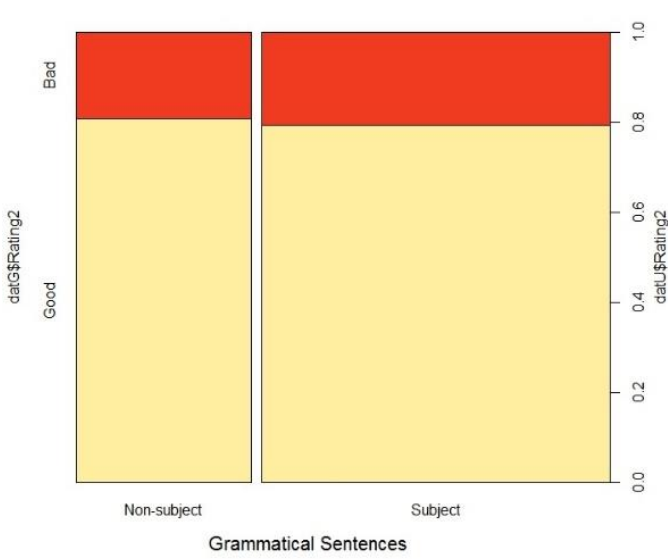

Figure 4: Acceptance Rates

The results of the auxiliary variable are listed in Table 7 and Figure 5. It is clear that Kurdish learners have successfully acquired these structures with a slight failure to reject the with $81 \%$ and $79 \%$ respectively, but again the learners have not succeeded to reject the ungrammatical sentences when the argument is non-subject. Almost half of the participants (46\%) accepted the non-subject ungrammatical sentences. It is to be noted that these ungrammatical sentences are compatible with grammatical structures in L2ers' L1. 
Table 7: Acceptance Rates of the Auxiliary Support

\begin{tabular}{|c|c|c|c|c|c|c|c|c|}
\hline \multirow{3}{*}{$\begin{array}{l}\text { Rating } \\
1 \text { (Good) }\end{array}$} & \multicolumn{4}{|c|}{ No Auxiliary } & \multicolumn{4}{|c|}{ With Auxiliary } \\
\hline & \multicolumn{2}{|c|}{ Grammatical } & \multicolumn{2}{|c|}{ Ungrammatical } & \multicolumn{2}{|c|}{ Grammatical } & \multicolumn{2}{|c|}{ Ungrammatical } \\
\hline & $81 \%$ & 194 & $37 \%$ & 234 & $80 \%$ & 573 & $0 \%$ & 0 \\
\hline 2 (Bad) & $19 \%$ & 46 & $63 \%$ & 406 & $20 \%$ & 147 & $0 \%$ & 0 \\
\hline
\end{tabular}

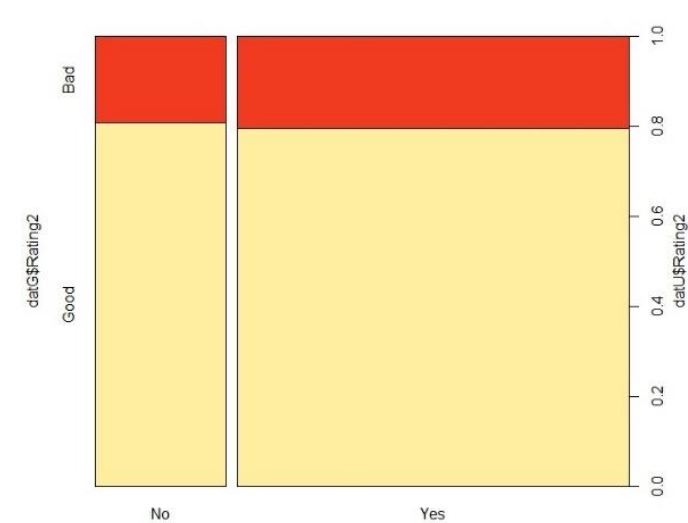

Grammatical Sentences

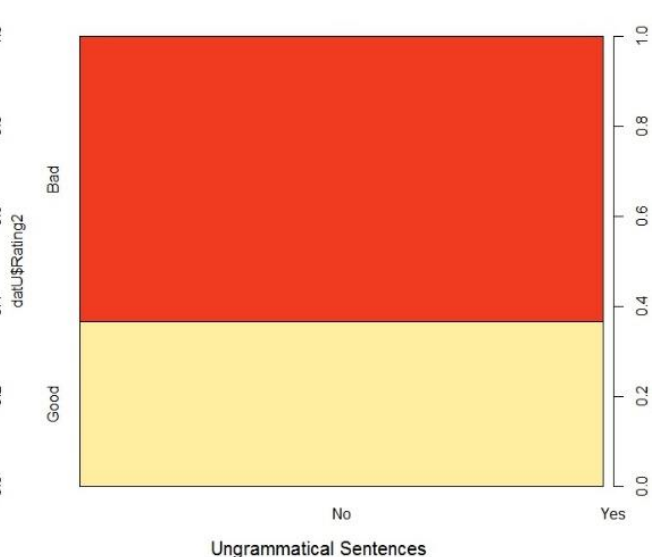

Ungrammatical Sentences

Figure 5: Acceptance Rates of the Auxiliary Support

The preliminary analysis of the results above shows that most participants, without taking their English proficiency level into account, acquired the correct parameters of almost all the variables, including the question type, the I-to-C movement, the argument structure, and the auxiliary. However, almost half of the learners have not been able to reject the ungrammatical sentences in all the variables. Some of the main ungrammatical sentences in English which correspond to grammatical literal counterparts in Kurdish that were presented in the JET are illustrated in (15) below. This seems to be a trending result from the participants.

(15) a. They paid you why?

b. The sentence means what?

c. You go to work when?

d. She lives where?

The Kurdish sentences that are equivalents to (15) and are considered grammatical in Kurdish are presented in (16).

(16) a. Wan boçî pare dane te?

they why money gave you

"Why did they pay you?" $\begin{array}{lll}\text { b. Raman-a } & \text { rist-ê } & \text { çîye? } \\ \text { meaning-Ez.Masc.SG sentence-OBL what }\end{array}$

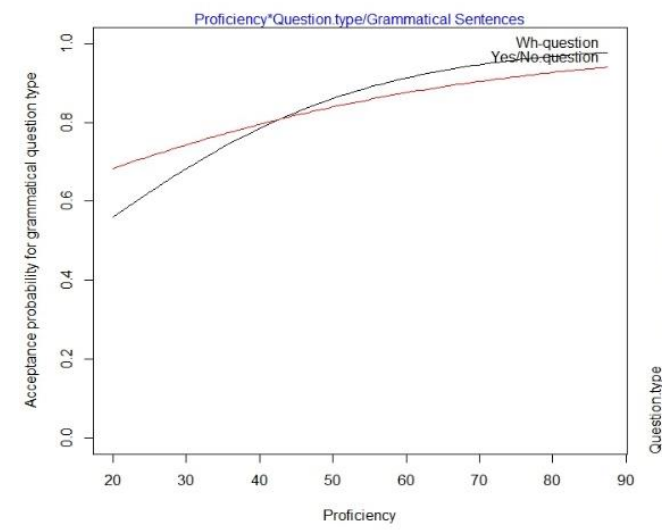

"What is the meaning of the sentence?"

c. Tu kengî di-çîy-e kar-î? you when PRST-go-2SG work-OBL

"When do you go to work?"

d. Ew kîve di-jî-t?

he where PRST-live-2SG

"Where does he live?"

However, the vast majority of the informants were sensitive to the ungrammatical Yes/No questions, which do not involve any I-to-C movement. Therefore, the participants rejected the ungrammatical Yes/No questions, unlike the Wh-questions.

\subsection{Effect of Participants' language proficiency:}

The analysis below will show what effect Kurdish lerarners' English language proficiency had on their judgements.

Figure 6 illustrates the effect of a three-way interaction of question type (Wh-question vs. Yes/No question), proficiency (L2ers' English language level), and grammaticalness (grammatical vs. ungrammatical).

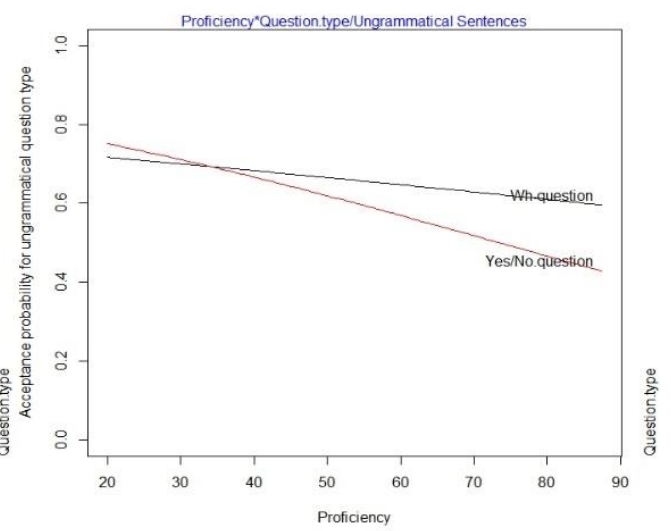

Figure 6: The effect of question type and proficiency 
In general, Kurdish learners of English accepted more grammatical Wh-questions than Yes/No questions, and they rejected more Yes/No questions than Wh-questions. As for ungrammatical sentences, Yes/No questions have been accepted more than Wh-questions.

It is clear that in both grammatical and ungrammatical sentences acceptance rates correlate with proficiency. This means that with the increase of participants' English language proficiency level, grammatical sentences are accepted more and ungrammatical sentences are rejected more. This means that with the increase of the proficiency level acceptance rates increase. More specifically, when the sentences are ungrammatical, highly proficient participants respond with rejection.

Figure 7 previews the effect of a three-way interaction of I-to$\mathrm{C}$ movement (Wh-movement vs. Wh-in-situ), proficiency (L2ers' English language level), and grammaticalness (grammatical vs. ungrammatical).

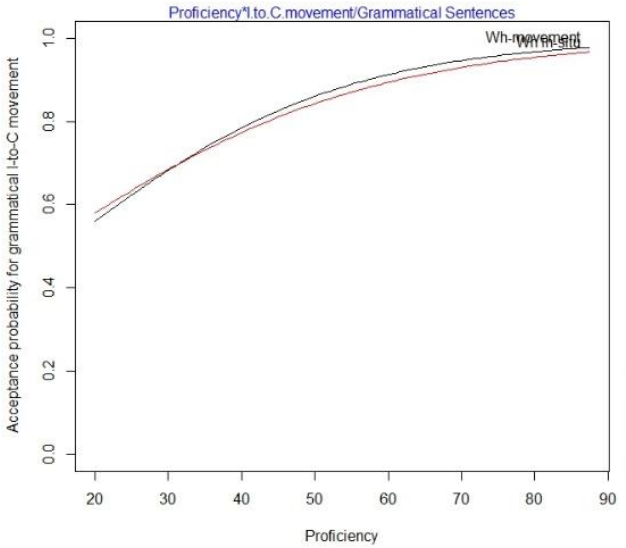

Figure 7: The effect of I-to-

Figure 7 shows that there is no significant difference in the acceptance rates regarding grammatical Wh-movement and Wh-in-situ sentences. Proficiency seems to be effective in enhancing the acceptance rates for both levels, though. This means that the acceptance rate for grammatical sentences increases with the increase of participants' English language proficiency.

On the other hand, with the ungrammatical sentences participants tend to highly accept Wh-movement sentences and proficiency does not seem to have a significant effect. As for Wh-in-situ sentences, less proficient learners' acceptance rates categorically increases. The rejection rate for ungrammatical Wh-in-situ sentences highly increases with the increase of participants' proficiency level.

\subsection{General Discussion:}

The acceptability judgement task conducted in this study addressed the issue of English verb/auxiliary movement to C and the "support" verb in the English complex predicate, realised as do-support in an attempt to show the interlanguage developed by Kurdish learners of English interrogation. It included Kurdish speaking learners of English $(\mathrm{p}=40)$. The judgement was based on a 2-point rating scale. 40 test items (in the form of question sentences) were presented.

This section is structured around the hypotheses and original research questions to provide adequate answers to those questions one by one.

\subsubsection{Acquisition of the auxiliary support by Kurdish} learners:

An auxiliary element is needed in English to support the Whwords that move from I to $\mathrm{C}$, but this does not happen in Kurdish. Research question \#1, copied below, was raised to investigate whether Kurdish learners will acquire this or not.

$R Q$ \#1: How do Kurdish learners of English reanalyse the "support" verb in their complex predicate, especially in relation with English do-support?

Kurdish learners have acquired the support of auxiliary verbs in both Wh-questions and Yes/No questions. However, there are participants (specifically the beginners) who failed to decline the ungrammatical sentences containing no auxiliary elements (see Figure 5). This shows that there is a negative

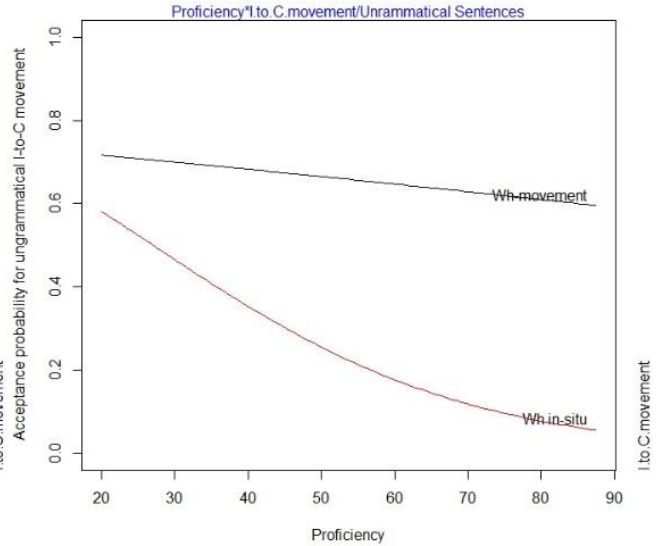

movement and proficiency

transfer from Kurdish L1 to the interlanguage developed by less proficient Kurdish learners.

It seems that Kurdish learners have succeeded to acquire the English syntactic properties regarding the auxiliary support, and this is in line with the Direct Access theory (Epstein et al., 1996). However, the failure to decline the absence of an auxiliary element by the less proficient learners can be interpreted by the FA/FT theory (Schwartz \& Sprouse, 1996), which posits L1 transfer and considers the L1 grammar to be the starting point for the acquisition of $\mathrm{L} 2$.

6.2.2 Acquisition of Wh-movement by Kurdish learners: Research question \#2 is set to investigate how Kurdish learners are going to interpret the Wh-fronting that happens in Whdependencies in English in which the Wh-question word moves from the inflection (I) to the complement (C) position. This syntactic property works the other way around in Kurdish; which, being a Wh-in-situ language, it involves no Whmovement.

(2) How do Kurdish learners of English acquire verb/auxiliary movement to $C$ ?

Kurdish learners have been successful in setting the correct Wh-movement parameter, but $64 \%$ of participants have failed to reject the ungrammatical Wh-movement sentences. Kurdish learners have also been successful in their acquisition process of grammatical Wh-in-situ sentences, and interestingly they have been able to reject the ungrammatical Wh-in-situ sentences too (See Figure 3). This shows that the majority of Kurdish learners transferred their Wh-in-situ parameter into their English interlanguage. Proficiency, as discussed below, does not seem to have an effect in enhancing the rejection rate of ungrammatical Wh-movement sentences. Therefore, this supports the claims made by the FA/FT theory (Schwartz \& Sprouse, 1996) because the L1 transfer is triggered and the L1 grammar is obviously the starting point for the acquisition of English I-to-C movement.

6.2.3 Effect of Kurdish learners' English language proficiency:

The effect of English language proficiency level of Kurdish learners is investigated by Research Question \#3, which states: (3) Will there be a systematic development by Kurdish learners of English in the process of acquiring Wh-questions and Yes/No questions? 
Proficiency was effective in accepting the grammatical Yes/No questions and Wh-questions and in rejecting their ungrammatical counterparts. This is because in both grammatical and ungrammatical sentences, acceptance rates correlate with proficiency, meaning that with the increase of participants' English language proficiency level, grammatical sentences are accepted more and ungrammatical sentences are rejected more (see Figure 6).

As for I-to-C movement, proficiency only partially affects the judgement rates. While proficincy shows a clear effect in increasing the acceptance rates regarding grammatical Whmovement and Wh-in-situ sentences, it does not have a significant effect in decreasing the high acceptance rate of the ungrammatical Wh-movement sentences, so Kurdish learners over accepted the ungrammatical sentences at lower proficiency levels. On the other hand, proficiency seems to lead to increase the rejection rate for ungrammatical Wh-in-situ sentences (see Figure 7).

\section{Conclusions}

This study comes up with a number of conclusions that are listed below:

1. The majority of Kurdish learners have acquired auxiliary support in English interrogation. However, there is a negative transfer from Kurdish L1 by beginners into their English interlanguage concerning the acquisition of the do-support in English interrogation.

2. The majority of Kurdish learners have successfully acquired Wh-movement and Wh-in-situ sentences. However, Kurdish learners over accepted the ungrammatical Wh-movement sentences at lower proficiency levels. Thus, a negative transfer from Kurdish L1 into beginners' English interlanguage is triggered again.

3. The proficiency level of L2ers' English language affects their acquisition representations in that acceptance rates of grammatical sentences increase with the increase of the proficiency level on one hand, and the rejection rates of ungrammatical sentences increase with the increase of the proficiency level on the other.
4. The results mentioned above lead to the conclusion that the predictions made by different SLA theories regarding the role of transfer and the ultimate attainment to explore whether it is possible for L2 learners to acquire L2 syntactic properties are fulfilled. For example, the FA/FT theory (Schwartz \& Sprouse, 1996) which posits L1 transfer and considers the L1 grammar to be the starting point for the acquisition of L2 has been fulfilled (the acquisition of auxiliary-support in English interrogation). The predictions of the Direct Access theory (Epstein et al., 1996) have also been fulfilled in which UG is taken to be the starting point for the acquisition of L2 (the acquisition of English I-to-C movement).

\section{References:}

Epstein, S., Flynn, S. \& Martohardjono, G. (1996). Second language acquisition: theoretical and experimental issues in contemporary research. Brain and Behavioral Sciences 19: 677-758.

Hawkins, R. (2011). Statistical learning and innate knowledge in the development of second language proficiency: evidence from the acquisition of gender concord. In A.G. Benati, (Ed.) Issues in second language proficiency. Clevedon: Multilingual Matters.

Schwartz, B. D., \& Sprouse, R. A. (1996). L2 cognitive states and the full transfer/full access model. Second Language Research, 12(1), 40-72.

Slabakova, R. (2008). Meaning in the Second Language, Studies in Language Acquisition Series, Berlin: Mouton de Gruyter.

Tsimpli, I. M., \& Dimitrakopoulou, M. (2007). The interpretability hypothesis: Evidence from whinterrogatives in second language acquisition. Second Language Research, 23, 215-242.

White, L. (2003). Second language acquisition and Universal Grammar. Cambridge: University Press.

Yang, C. D. (2002). Knowledge and Learning in Natural Language. New York: Oxford University Press. 
Appendix 1: The Jury

\begin{tabular}{|l|l|l|l|}
\hline No & Name & Academic Status & University \\
\hline 1 & $\begin{array}{l}\text { Dr. Alya' Muhammad Husain } \\
\text { Ahmed }\end{array}$ & Professor in Translation & University of Duhok \\
\hline 2 & Dr. Muhammad Salih Abdullah & Assistant Professor in Linguistics & University of Duhok \\
\hline 3 & Dr. Saeed Adres Saeed & $\begin{array}{l}\text { Assistant Professor in Phonetics } \\
\text { and Phonology }\end{array}$ & University of Duhok \\
\hline
\end{tabular}

Appendix 2: The Grammaticality Judgement Task

Please fill in the following details about yourself?

1. Age:

2. Gender: (Male - Female).

3. Mother tongue:

4. Educational level:

5. Other languages spoken:

6. Current usage of English:

(daily - a few times a week - a few times a month - rarely - not at all).

Now, please read each sentence and determine if each sentence is Grammatical or Ungrammatical by checking the option you select:

\begin{tabular}{|c|c|c|c|}
\hline \# & Sentences & Grammatical & Ungrammatical \\
\hline 1 & Do they live in Australia? & & \\
\hline 2 & How many workers you know in that factory? & & \\
\hline 3 & They paid you why? & & \\
\hline 4 & What does the sentence mean? & & \\
\hline 5 & Which car you like? & & \\
\hline 6 & Does he hate basketball? & & \\
\hline 7 & Has she done the housework? & & \\
\hline 8 & The sentence means what? & & \\
\hline 9 & Now I have to finish this letter. & & \\
\hline 10 & She the housework done? & & \\
\hline 11 & He basketball hates? & & \\
\hline 12 & Why did they pay you? & & \\
\hline 13 & Who the doctors you met? & & \\
\hline 14 & You this morning to the bank went? & & \\
\hline 15 & You go to work when? & & \\
\hline 16 & What happened to your face? & & \\
\hline 17 & Were they ready to leave? & & \\
\hline 18 & My favourite hobby is playing snooker. & & \\
\hline 19 & Are you waiting for someone? & & \\
\hline 20 & They ready to leave? & & \\
\hline 21 & He the book will read? & & \\
\hline 22 & What your face reflects? & & \\
\hline 23 & What makes you angry the most? & & \\
\hline 24 & What does your face reflect? & & \\
\hline 25 & How many workers work in that factory? & & \\
\hline 26 & Will he be reading the book? & & \\
\hline 27 & I got a new computer for my birthday. & & \\
\hline 28 & Is your friend staying at the hotel? & & \\
\hline 29 & They in Australia live? & & \\
\hline 30 & Which car do you like? & & \\
\hline 31 & $\begin{array}{l}\text { How many workers do you know in that } \\
\text { factory? }\end{array}$ & & \\
\hline 32 & Who won the championship yesterday? & & \\
\hline 33 & Where does she live? & & \\
\hline 34 & She lives where? & & \\
\hline 35 & Who are your best friends? & & \\
\hline 36 & When the weather is bad, John reads books. & & \\
\hline 37 & Who were the doctors you met? & & \\
\hline 38 & Who is the best football player in the world? & & \\
\hline 39 & Which university accepted you? & & \\
\hline 40 & You someone be waiting? & & \\
\hline 41 & Who came late? & & \\
\hline 42 & Your friend at hotel is staying? & & \\
\hline 43 & Did you go to the bank this morning? & & \\
\hline 44 & When do you go to work? & & \\
\hline 45 & My friends and I don't get very good marks. & & \\
\hline
\end{tabular}




\section{Appendix 3: The Proficiency Test}

\section{Grammar I}

Instructions: Select the correct answer.

1. Juan__ in the library this morning.
(A) is study
(B) studying
(C) is studying
(D) are studying

2. Alicia, the windows please. It's too hot in here.
(A) opens
(B) open
(C) opened
(D) will opened
3. The movie was the book.
(A) as
(B) as good
(C) good as
(D) as good as

4. Eli's hobbies include jogging, swimming, and
(A) to climb mountain
B) climb mountain
(C) climbing mountains
(D) to climb

5. Mr. Hawkins requests that someone the data by fax immediately.
(A) sent
(B) sends
(C) send
(D) to send

6. Who is Marina or Sachiko?
(A) tallest
(B) tall
(C) taller
(D) the tallest

7. The concert will begin fifteen minutes.

(C) with

(D) about

8. I have only a Christmas cards left to write.
(A) few
(B) fewer
(C) less
(D) little

9. Each of the Olympic athlete for months, even years.
(A) have been training
(B) were training
(C) has been training
(D) been training
10. Maria never late for work.
(A) am
(B) are
(C) were
(D) is

11. The company will upgrade____ computer information systems next month.
(A) there
(B) their
(C) it's
(D) its

12. Cheryl likes apples, she does not like oranges
(A) so
(B) for
(C) but
(D) or

13. You were the New York office before 2 p.m.
(A) suppose call
(B) supposed to call
(C) supposed calling
(D) supposed call

14. When I graduate from college next June, I a student here for five years.
(A) will have been (B) have been
(C) has been
(D) will have

15. Ms. Guth rather not invest that money in the stock market.
(A) has to
(B) could
(C) would
(D) must

\section{Grammar II}

Instructions: Select the underlined word or phrase that is incorrect.

1. The majority to the news is about violence or scandal.
(A) The
(B) to
(C) news
(D) violence

2. Takeshi swimmed one hundred laps in the pool yesterday.
(A) swimmed
(B) hundred
(C) in
3. When our vacation, we plan to spend three days scuba diving.
(A) When
(B) plan
(C) days
(D) diving
4. Mr. Feinauer does not take critical of his work very well.
$\begin{array}{lll}\text { (A) does } & \text { (B) critical (C) his }\end{array}$
(D) well

(D) yesterday

5. Yvette and Rinaldo send e-mail messages to other often.
(A) and
(B) send
(C) other
(D) often
6. Mr. Olsen is telephoning a American $\underline{\operatorname{Red}}$ Cross for help.
(A) is

(B) a

(C) Red

7. I had a enjoyable time at the party last night.
(A) a
(B) time
(C) at
(D) last

8. The doctor him visited the patient's parents.
(A) The
(B) him
(C) visited
(D) patient's

9. Petra intends to starting her own software business in a few years
(A) intends
(B) starting
(C) software

10. Each day after school, Jerome run five miles.
(A) Each
(B) after
(C) run
(D) miles
11. He goes never to the company softball games.

$\begin{array}{lll}\text { (A) never (B) the } & \text { (C) softball }\end{array}$

12. Do you know the student who books were stolen?
(A) Do
(B) know
(C) who
(D) were

(D) games
13. Jean-Pierre will spend his vacation either in Singapore nor the Bahamas.
(A) will
(B) his

(C) nor

14. I told the salesman that I was not interesting in buying the latest model.
(A) told
(B) that
(C) interesting

(D) Bahamas

15. Frederick used work for a multinational corporation when he lived in Malaysia.
(A) used work
(B) multinational
(C) when
(D) lived in

\section{Vocabulary}

Instructions: Select the best answer.
1. The rate of
has been fluctuating wildly this week.

A.

money 


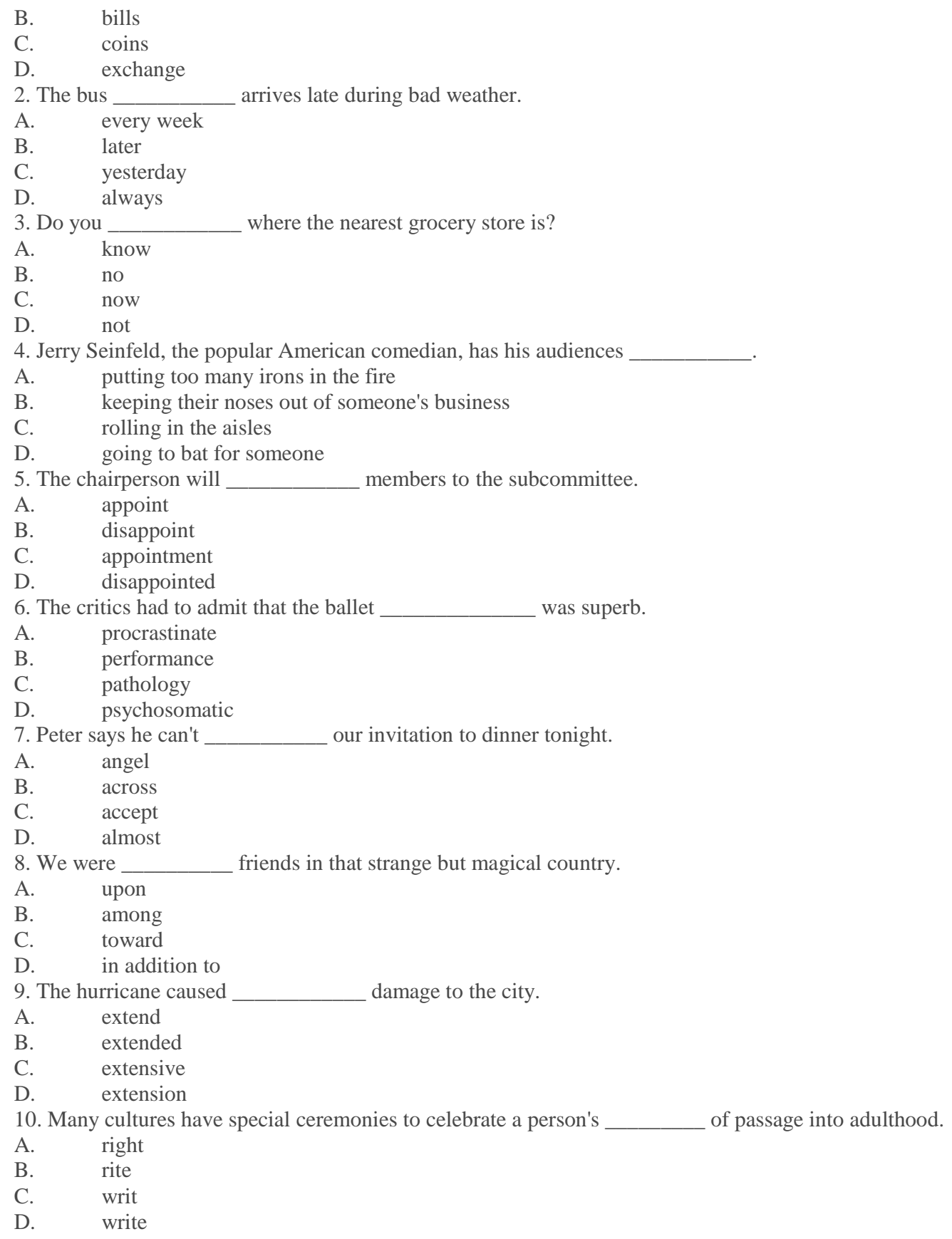

\section{Appendix 4: List of Abbreviations}

The abbreviations used in the study are listed below:

COMP: Complementizer

DIR: Direct Case

EZ: Ezafe Particle

FA/FT: Full Access Full Transfer Theory

I-to-C: Inflection-to-Complementizer

JET: Judgement Elicitation Task

L1: First Language

L2: Second Language

OBL: Oblique Case

PL: Plural

PRST: Present

SG: Singular

SLA: Second Language Acquisition

UG: Universal Grammar 


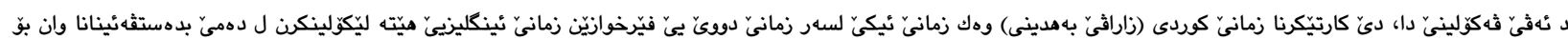

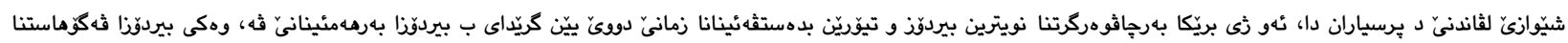

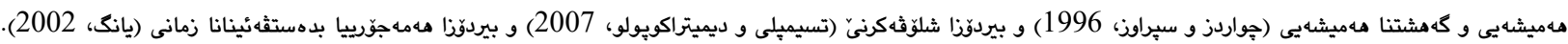

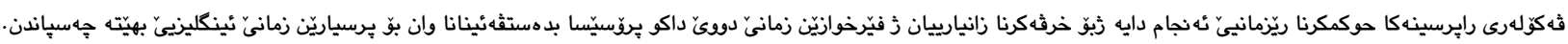

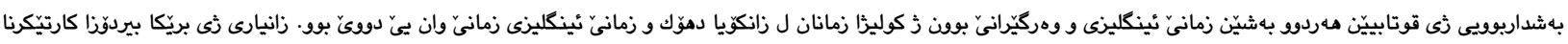

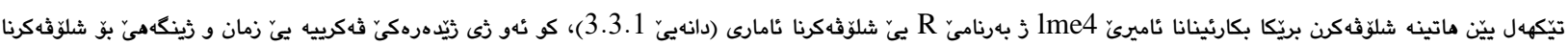

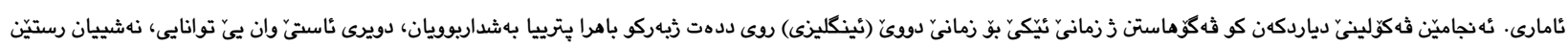

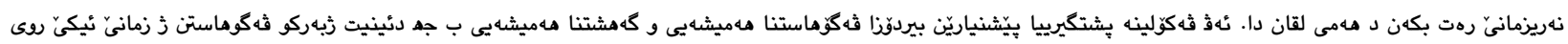

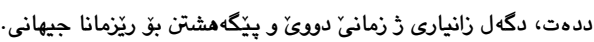

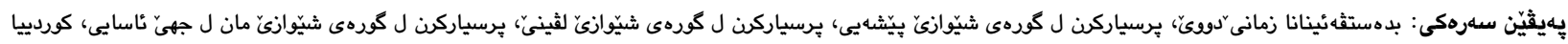
بهدينى، ريزمانا جيهانى.

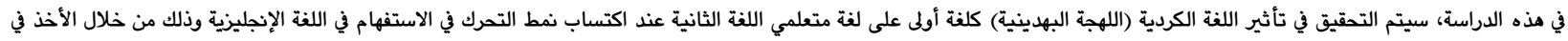

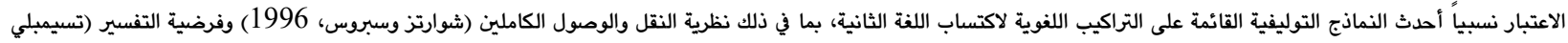
وديميتراكوبولو، 2007) والنموذج المتفير لاكتساب اللغة (يانغ، 2002).

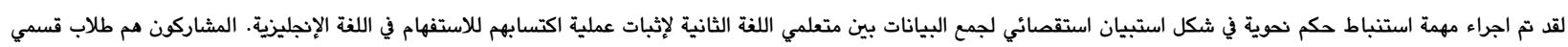
اللغة الإنجليزية والترجمة من كلية اللغات بجامعة دهوك، حيث إن إن اللغة الإنجليزية هي لغتهم الثانية.

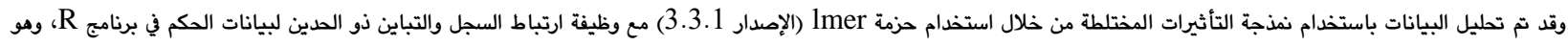
عبارة عن برنامج لغة مفتوحة المصدر وبيئة للحوسبة الإحصائية.

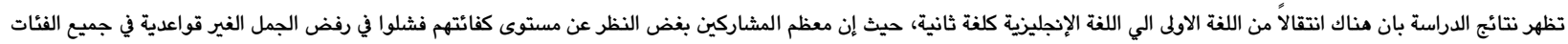

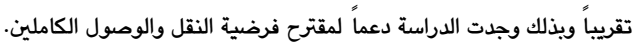

الكلمات الدالة: اكتساب اللغة الثانية، الاستفهام القائم على النمط المتقدم، الاستفهام القائم على نمط التحريك، الاستفهام القائم على نمط البقاء في الموقع الطبيعي، اللغة الكردية البهدينية، 